\title{
Teaching Case Base Construction of Airport Security Inspection Enterprise Production Practice under Post Business Process
}

\author{
Ma Chunting \\ Sanya Aviation\&Tourism College, Sanya, 572000, China
}

Keywords: Post business process; Airport security inspection; Enterprise production practice; Teaching case base

\begin{abstract}
With the development of national economy, civil aviation industry entered the spring of development and constituted an important part of modern service industry. Under the background of national "One Belt and One Road" initiative, the development of civil aviation industry is facing a broader space for development. The security inspection of the airport gradually obtains people's attention, so in training process in colleges and universities, teaching case base for airport security inspection enterprise production practice can be constructed based on post business process. This paper carries out corresponding analysis.
\end{abstract}

In the development of civil aviation industry, security is a top priority. Under the strategic deployment of building a powerful nation with civil aviation in our country, civil aviation has made great strides. In recent social news, there have been many cases of hidden dangers in aviation security that put aviation security on the peak of public opinion. Therefore, security inspection of civil aviation should be strengthened and professional security regulations should be strictly followed.

\section{Necessity analysis of the construction of airport security inspection enterprise production practice teaching case library}

\subsection{Civil aviation industry's social concern is relatively high}

According to the statistics bulletin of civil aviation industry in 2014, a total of 202 transport airports were issued in our country, an increase of 9 over 2013. In 2014, CAC completed 832 million passenger throughputs, including 24 airports with more than 10 million flights and 40 airports with 1 million to 10 million passengers. According to the matching of at least 700 screeners at 10 million airports, airport security inspectors have become one of the scarce civil aviation personnel in recent years.

According to the relevant data from the Ministry of Education Information Center, the highest employment rate of civil aviation higher vocational colleges in 2012-2014 is civil aviation security and technical management major, ranking the first place for three consecutive years. In 2012-2014, the enrollment statistics of all civil aviation higher vocational majors also showed that the enrollment of civil aviation security technology management and airport security inspection professionals has been increasing year by year. For example, Sanya Aviation Tourism College, civil aviation security and technical management professionals admitted more than 500 students in 2015, a total of more than 1100 students, becoming the largest school in the profession, which shows the profession's social attention and social recognition [1].

\subsection{Construction requirements for standard case teaching}

Our college has done lots of explorations and practices in the reform of personnel training mode such as the combination of work and study, school-enterprise cooperation and so on. It has accumulated rich experience in professional construction, curriculum construction and training base construction, and is the 021 occupation skill appraisal station authorized by CAAC, and for 8 consecutive years, it assumes Boao Asia Forum security inspections. In order to form a batch of 
production practice teaching resources that meet the training needs of high-quality technical and skill personnel in airport security inspection posts, so that high quality teaching resources can be shared across schools and regions and provide an unbounded service for students and employees in professional learning, our college will develop teaching case base on airport security inspections production practice, from point to area, and develop and promote airport security inspections production practice sharing teaching case base, "collect," "solidify," and "promote" teaching resources so as to further promote the development of education informatization.

\section{The significance of teaching case base construction}

Since 1870 Harvard Law School applied case teaching to college courses, this approach has gradually been applied in many disciplines. There are already some experts trying out technical-oriented majors in domestic higher vocational education in such fields as biochemistry, e-commerce, aerospace and travel medicine, but a systematic theory and normative mode of operation has not yet been formed [2]. At present, the state is vigorously promoting the construction of a shared teaching resources base. Since 2011, it has started the project construction of 5 teaching resources bases. However, through learning, we found that there are very few actual teaching cases in these resources. Vocational education is able to directly use the actual cases of enterprises for teaching is an effective way to realize the integration of production and teaching and "Five Docking" [3].

\section{Teaching case construction of airport security inspection enterprise production practice under post business process}

\subsection{Post business process theory overview}

Business Process Management (BPM) can be used to optimize the combination of all aspects of the enterprise and to achieve total management. It covers equipment, personnel, and desktop applications, and can fully implement its system's optimized combination and achieve cross-departmental, cross-application and cross-partner and customer operations, enabling continuous optimization of information delivery, data synchronization, internal business processes and business monitoring. The application of BPM can make full use of work-flow transfer and process monitoring in traditional industrial organization. Full attention is given to technical bottleneck in traditional work-flow and effective solution is applied. Business management and work-flow technology are made full use of. Business process theory can improve the efficiency of business process for the enterprise. Business process management is to arrange jobs based on poses in the enterprise. The proposition of business process reengineering challenged the traditional division of labor. In 1993, James Ciampi and Michael Hammer put forward classic business process reengineering theory in "Reengineering Company: The Revolution of Enterprise Revolution", which points out that the theory of business process reengineering is a redesign and rethink of the original business process from the aspects of speed, cost, service and quality, so that the business can make significant headway. Business Process Reengineering Theory includes six stages: strategic decision-making phase, reconstruction planning phase, process diagnosis phase, re-design phase, and reconstruction phase and evaluation effectiveness. The implementation of business process reengineering theory includes two ways: gradual implementation and reengineering. According to relevant statistics, in actual effective processing time during one project operation, real process time is $10 \%$, and the remaining $90 \%$ of the time is stagnant time. If the operation of the process depends on manual telephone and legs Contact, it needs to spend a lot of manpower costs and economic costs and the effect is more limited, and there will be the phenomenon of missing documents. Through the use of post business process management can make full use of the mature technology and computer technology to meet the needs of enterprises in this area; through the operation of information entry circulation rules can be made full use of to enhance the full progress of enterprise business processes. 
In the operation of traditional functional departments, different departments have corresponding application scope and development advantages. The coordinated development of enterprises as a whole requires the coordinated development among different departments, including production department, purchasing department, financial department and senior management department. In addition to the collaboration between different departments, there is also a need to strengthen the set appropriate content of jobs in accordance with different positions.

\subsection{The implementation process of teaching case}

In the organization process of enterprise production practice teaching cases, civil aviation screeners national standards is taken as the basis and the entire security inspection process is taken as the framework for the construction of teaching resources. According to the requirements of business process theory, the following teaching case design of airport security inspection enterprises production practice can be carried out. The construction contents include four aspects: the standard of airport security case base, the teaching case base of airport security inspection production practice, the cooperation between school and enterprise and network platform. Among them, the teaching case base of airport security inspection production practice is the core task of the case base construction.

The top-level design is the standard of airport security case base. According to the national standards of civil aviation security inspectors, the standard of personnel training is determined, and a multi-layer frame structure that meets the needs of teachers, students and enterprises is formed.

The construction of teaching case base of airport security inspection production practice is divided into two parts: passenger inspection and cargo inspection. There are 6 sub-categories. The preliminary plans are as follows: The first is verification inspection, which includes: identity card problems including counterfeit, expired and non-personal ID cards. The issue of boarding pass is manifested at the wrong boarding airport or terminal, non-personal boarding pass, incorrect departure date, non-electronic boarding pass, etc. Other documentary issues such as military ID, passport and air ticket problems. The second is physical examination, including: the carrying of the nine categories of goods which are prohibited by the state, goods that cannot be carried on but can be shipped and the new regulations banned items after the introduction of these two provisions, such as $100 \mathrm{ml}$ liquid, ignition equipment, and irregularities Charging treasure. The third is carry-on goods inspection. The state prohibits nine categories of items, and there are regulations about goods prohibited by the state to carry on but can be shipped, goods with limited national restrictions, and other items prohibited by the new regulations such as $100 \mathrm{ml}$ liquid, ignition equipment, illegal charging treasure and so on. The fourth is to inspection shipped baggage, and there are nine categories of items of national prohibition, goods of national restrictions, and other provisions prohibited items such as $100 \mathrm{ml}$ liquid, ignition equipment, illegal charging treasure and so on. The fifth is the inspection of nine categories of items of national prohibition, goods of national restrictions, and other provisions prohibited items. The sixth is other cases, such as leakage cover inspection stamps, terminal inventory problems, and equipment use problems. This item is mainly used for inspection vacancy. If there are outstanding problems in the practice of research, they can be a separate category [4].

The specific implementation process includes four stages. The first stage is to carry out the top-level design to form a multi-layer framework to meet the needs of teachers, students, business users. The second stage is the establishment of case base directory, collecting case material, and with integrated induction to make a variety of material forms. The third stage is to build a network service platform. The fourth stage is to promote the use and continuous improvement.

\subsection{The development advantages and teaching achievements of teaching case base}

The use of such a teaching project is our school civil aviation's twenty-first occupation skill appraisal station, which is developed based on civil aviation screeners' national standards to standards for standardized construction. Taking Hainan Airlines' dozens of airports as a platform, the entire security inspection process as a framework, our college's teaching resource base is systematically built. Through the cooperation platform of schools and civil aviation airports, we 
showcase the latest and most complete civil aviation security inspection and production practice cases to meet the needs of students and employees training and other needs; the use of network services platform is to meet the teaching case base for student learning, teacher teaching, and enterprise staff training, to achieve school-enterprise resource sharing; from point to area, security major teaching case base construction is as a pilot to gradually be extended to other majors and achieve further reform of practical teaching.

The development advantage of this teaching case is mainly manifested in the clear objectives of professional training based on civil aviation screeners' national standards with advantages of school-enterprise cooperation, relying on Hainan Airline Group, airport security practices as a guide. Training platform is opened to beneficiary cover students and front-line staff.

The expected accomplishments and effects are achieved through such project implementation, including the form of results, the expected roll-out and scope of application. Case library manifestations include: picture material, such as forged documents, dangerous goods, etc.; video material, such as enterprise practical production operation video; animation materials, workflow, principles and other teaching animations; virtual training material, virtual training programs; business case text material; courseware material used in practical teaching of multimedia courseware; exercise materials, the development of test database. The completed case library will be used for the study and verification training of students in security inspection at the airport and may also be used for pre-service training and lifelong learning for front-line security staff as well as public security bureaus, security guards and high-speed rail stations that need to undergo security screening training.

\section{Conclusions}

The teaching of aviation security inspection major should fully combine enterprise's actual development. Make full use of business process concept, create sufficient opportunities for students to develop, and create sufficient opportunities for their theoretical application. The teaching methods of enterprise production practice teaching case base construction can fully realize this teaching goal and have important practical significance.

\section{Acknowledgements}

Fund project: 2016 institutions of higher learning education teaching reform project of hainan province Project name: airport security checks professional enterprise producing putted forward the development of practical teaching research (number: Hnjg2016-94)

\section{References}

[1] Shi Yuehong, Ma Chunting. Research on the Construction of Teaching Case Database for Airport Security inspection Specialty Production Practice [J]. Business Air Transportation, 2017 (8): 62-64.

[2] Huang Ning. Construction of Enterprise Production Practice Teaching Case Base based on Post Business Process - Taking the Case Study of Automotive Marketing and Service Major [J]. Education and Teaching Forum, 2017 (9): 87-88.

[3] Zheng Ning, Tang Xiaohua. New Energy Enterprise Production Practice Teaching Case Base Construction and Research [J]. Wind Energy, 2016 (5): 38-40.

[4] Liu Yanzhi, Qi Yuyu, Li Qingjun. Higher Vocational School Tourism Japanese Major Enterprise Production Practice Teaching Case Base Construction [J]. Courses Education Research: New Teachers Teaching, 2015 (30). 